\title{
UEFA injury study: a prospective study of hip and groin injuries in professional football over seven consecutive seasons.
}

\author{
J Werner, Martin Hägglund, Markus Waldén and Jan Ekstrand
}

\section{Linköping University Post Print}

\section{Tweet}

N.B.: When citing this work, cite the original article.

Original Publication:

J Werner, Martin Hägglund, Markus Waldén and Jan Ekstrand, UEFA injury study: a prospective study of hip and groin injuries in professional football over seven consecutive seasons, 2009, British journal of sports medicine, (43), 13, 1036-40.

http://dx.doi.org/10.1136/bjsm.2009.066944

Copyright: BMJ Publishing Group

http://group.bmj.com/

Postprint available at: Linköping University Electronic Press

http://urn.kb.se/resolve?urn=urn:nbn:se:liu:diva-52237 


\section{UEFA injury study: a prospective study of hip and groin injuries in professional football over seven consecutive seasons}

Jonas Werner, MD, Martin Hägglund, RPT, PhD, Markus Waldén, MD, PhD, Jan

Ekstrand, MD, PhD

Department of Medicine and Health Sciences, Linköping University, Linköping, Sweden.

Correspondence to:

Dr Jonas Werner

Department of Orthopaedics

Vrinnevisjukhuset

SE-603 79 Norrköping

Sweden

Email: jonas.werner@lio.se

Phone: +46 $736393919 \quad$ Fax: +4611 121334

Key words: groin injury, football, injury incidence, epidemiology, professional Word count: 2609 


\section{ABSTRACT}

Background: Groin injury is a common injury in football and a complicated area when it comes to diagnosis and therapy. There is a lack of comprehensive epidemiological data on groin injuries in professional football.

Objective: To investigate the incidence, pattern and severity of hip and groin injuries in professional footballers over seven consecutive seasons.

Study design: Prospective cohort study.

Setting: European professional football.

Methods: During the 2001/02-2007/08 seasons between nine and 17 clubs per season (23 clubs in total) were investigated, accounting for 88 club seasons in total. Time loss injuries and individual exposure during club and national team training sessions and matches were recorded.

Main outcome measure: Injury incidence.

Results: A total of 628 hip/groin injuries were recorded, accounting for $12-16 \%$ of all injuries per season. The total injury incidence was $1.1 / 1000$ hours $(3.5 / 1000$ match hours $\mathrm{v}$ 0.6/1000 training hours, $\mathrm{p}<0.001$ ) and was consistent over the seasons studied. Eighteen different diagnostic entities were registered, adductor $(n=399)$ and iliopsoas $(n=52)$ related injuries being most common. More than half of the injuries (53\%) were classified as moderate or severe (absence of more than a week), the mean absence per injury being 15 days. Reinjuries accounted for $15 \%$ of all registered injuries. In the 2005/06-2007/08 seasons, $41 \%$ of all diagnoses relied solely on clinical examination.

Conclusions: Hip/groin injuries are common in professional football and the incidence over consecutive seasons is consistent. Hip/groin injuries are associated with long absences. Many hip/groin diagnoses are based only on clinical examination. 
Word count: 249 


\section{INTRODUCTION}

Although a common injury in football, with reported annual incidences of between 5-28\%, ${ }^{1-7}$ groin injuries still often elude football medicine practitioners due to the difficulties of diagnosis and treatment. To our knowledge, no modern prospective study has been able to confirm the sometimes mooted increase in groin injury incidence in sports in general and football in particular. ${ }^{8}$

Not seldom a cause of long periods of absence, ${ }^{1}$ groin injuries often present diffuse and vague symptoms that call for a multidisciplinary approach. ${ }^{9}$ There is a lack of consensus on diagnostic criteria and definitions of groin injuries, making comparisons between studies difficult. ${ }^{10-11}$ However, most authors agree that acute groin injuries and longstanding groin pain due to overuse are two main categories. In addition, there is a lack of comprehensive prospective epidemiological studies of groin injuries in football. The existing studies in this area tend to comprise a rather small number of cases, ${ }^{1,3-4,12-15}$ study non-professional players, ${ }^{14}$ or deal with patients referred to a clinic. ${ }^{16}$ One large prospective study found hip/groin injuries to account for $12 \%$ of all injuries in the top four English leagues. ${ }^{6}$ The aim of the present study was to prospectively investigate the incidence, pattern and severity of groin injuries in European professional football over seven consecutive seasons. 


\section{MATERIALS AND METHODS}

A prospective cohort study of European professional football was carried out over seven consecutive seasons, 2001/02-2007/08, and the overall results have recently been published. ${ }^{17}$ A total of 88 club seasons were included, involving 23 different clubs, five of which participated in all seven seasons. Teams participated in a mean (SD) of 3.8 (2.2) seasons (range 1-7). The methodology followed the consensus on injury definitions and data collection procedures in football studies ${ }^{18}$ and the UEFA (Union of European Football Associations) model, and has been reported in detail previously. ${ }^{19}$ Accordingly, three forms were used for data collection; (1) a baseline form with player anthropometrics collected at the beginning of each season, (2) an injury card that was filled in immediately after the injury and sent to the study group each month, and (3) an exposure form where individual player exposure to match play and training was registered and sent in on a monthly basis.

\section{Study sample and study period}

All players in the first team squads each season were invited to participate. In total, 1065 players agreed to participate and provided signed written consent. Players injured at the start of their first season were included, but their present injuries were not taken into account. Players who left their club before the end of the season were included for as long as they participated. Details of participating clubs and player anthropometrics are available in a separate report. $^{17}$

\section{Data collection}

Baseline forms for anthropometric data and previous medical history were used, as were exposure registration forms and injury cards. A member of each club's medical team or 
technical staff registered individual exposure in minutes during club and national team training sessions and matches. The medical team recorded all injuries immediately after the incident and completed the injury cards (one general injury card and one groin-specific injury card, both adjusted to the consensus statement ${ }^{18}$ before the $2005 / 06$ season). From the 2005/06 season, information about diagnostic investigations conducted was also reported and confirmation of any clinical examination, X-ray, ultrasonography (US) and magnetic resonance imaging (MRI) was requested on the injury card along with space to enter free text. In addition, from the 2006/07 season it became mandatory to specify on the groin injury card whether the injury was due to trauma or overuse. Injury cards and attendance records were sent to the study group once a month.

\section{Definitions}

Definitions are outlined in Table 1. Re-injury was defined as an injury of the same type and location as a previous injury that occurred within two months of a player's return to full participation, later referred to as "early recurrence" in the consensus statement. ${ }^{18} \mathrm{~A}$ recordable hip/groin injury was defined as an injury located to the hip (hip joint or surrounding soft tissues) or groin (junction between the anteromedial part of the thigh, including the proximal part of the adductor muscle bellies, and the lower abdomen) resulting from playing football and leading to a player being unable to fully participate in future training or match play (i.e. time-loss injury). Each injury was coded according to a modified version of the Orchard Sports Injury Classification System (OSICS) $2.0,{ }^{20}$ which was established when the study started. The diagnoses enthesiopathy, groin tendinosis, femoroacetabular impingement and groin nerve entrapment were added by the study group. 
Table 1. Operational definitions.

\begin{tabular}{|c|c|}
\hline Training session & Team training that involved physical activity under the supervision of the coaching staff. \\
\hline Match & Competitive or friendly match against another team. \\
\hline Hip/groin injury & $\begin{array}{l}\text { Injury located to the hip joint or surrounding soft tissues or at the junction between the } \\
\text { anteromedial part of the thigh, including the proximal part of the adductor muscle bellies, and } \\
\text { the lower abdomen resulting from playing football and leading to a player being unable to fully } \\
\text { participate in future training or match play (i.e. time-loss injury). }\end{array}$ \\
\hline Rehabilitation & $\begin{array}{l}\text { A player was considered injured until club medical team allowed full participation in training and } \\
\text { availability for match selection. }\end{array}$ \\
\hline Re-injury & $\begin{array}{l}\text { Injury of the same type and location as a previous injury that occurred within two months of a } \\
\text { player's return to full participation. }\end{array}$ \\
\hline Minimal injury & Injury causing absence of 1-3 days from training and match play. \\
\hline Mild injury & Injury causing absence of 4-7 days from training and match play. \\
\hline Moderate injury & Injury causing absence of $8-28$ days from training and match play. \\
\hline Severe injury & Injury causing absence of over 28 days from training and match play. \\
\hline Traumatic injury & Injury with sudden onset and known cause. \\
\hline Overuse injury & Injury with insidious onset and no known trauma. \\
\hline Injury incidence & Number of injuries per 1000 player hours $[(\Sigma$ injuries $/ \Sigma$ exposure hours $) \times 1000]$. \\
\hline Dominant leg & Preferred kicking leg. \\
\hline
\end{tabular}

\section{Statistical analysis}

All quantitative variables were analysed using a one-way, factorial analysis of variance (ANOVA) and are presented as mean values (standard deviation). The $\chi^{2}$-test was used to analyse qualitative variables. Injury incidence is expressed as the number of injuries per 1000 hours of exposure and presented with $95 \%$ confidence intervals. A Z-test was used when analysing incidences between groups. To analyse the influence of age on hip/groin injury incidence, players were divided into four age-groups: <21, 21-25, 26-30 and >30 years. The significance level was set at $5 \%(\mathrm{p}<0.05)$. 


\section{RESULTS}

The mean age of the players was 26 (4), ranging from 16 to 40 years. The total exposure was 566000 hours (475 000 training hours and 91000 match hours). A total of 628 hip/groin injuries were recorded, representing between 12 and $16 \%$ of all injuries per season (Table 2).

The mean number of groin injuries per club was 7.2 (4.3) per season. The total groin injury incidence was 1.1/1000 hours (95\% CI 1.0-1.2) and was significantly higher during match play than training $(3.5 / 1000(3.1-4.0)$ v $0.6(0.5-0.7), \mathrm{p}<0.001)$. Ninety-four of the recorded groin injuries were re-injuries, accounting for almost $15 \%$ of all groin injuries.

Traumatic injuries constituted $66(27 \%)$ and overuse injuries $175(73 \%)$ of the 241 groin injuries recorded in the 2006/07 season.

The mean absence because of groin injury (all injuries included) was 15 (20) days; 16 (17) days for traumatic injuries and 14 (19) days for overuse injuries $(\mathrm{p}=0.45)$. The mean absence for re-injuries was significantly longer than for index injuries: 23 (27) v 14 (18) days $(\mathrm{p}<0.0001)$ 
Table 2 Hip/groin injury incidence and characteristics in European professional football.

\begin{tabular}{|c|c|c|c|c|c|c|c|c|}
\hline Season & $01 / 02$ & $02 / 03$ & $03 / 04$ & $04 / 05$ & $05 / 06$ & 06/07 & 07/08 & Total \\
\hline \multirow[t]{2}{*}{ No. of injuries (\%) } & $79 / 658$ & $72 / 454$ & $78 / 486$ & $54 / 384$ & $103 / 745$ & $134 / 924$ & $108 / 832$ & $628 / 4483$ \\
\hline & $(12 \%)$ & $(16 \%)$ & $(16 \%)$ & $(14 \%)$ & $(14 \%)$ & $(15 \%)$ & $(13 \%)$ & $(14 \%)$ \\
\hline No. of injuries per club* & $7.2(5.5)$ & $8.0(3.6)$ & $7.1(4.6)$ & $6.0(2.6)$ & $6.1(3.0)$ & $7.9(5.5)$ & $7.7(4.6)$ & $7.2(4.3)$ \\
\hline No. of re-injuries (\%) & $21(27 \%)$ & $8(11 \%)$ & $8(10 \%)$ & $5(9 \%)$ & $12(12 \%)$ & $23(17 \%)$ & $17(16 \%)$ & $94(15 \%)$ \\
\hline No. of injured players (\%) & $51(19 \%)$ & $48(22 \%)$ & $56(21 \%)$ & $42(19 \%)$ & $82(20 \%)$ & $102(22 \%)$ & $84(21 \%)$ & $465(21 \%)$ \\
\hline \multirow[t]{2}{*}{ Injury incidence $\dagger$} & 1.2 & 1.2 & 1.2 & 0.9 & 1.0 & 1.2 & 1.1 & 1.1 \\
\hline & $(0.7-1.6)$ & $(0.9-1.3)$ & $(0.9-1.4)$ & $(0.8-1.0)$ & $(0.9-1.1)$ & $(0.9-1.4)$ & $(0.8-1.4)$ & $(1.0-1.2)$ \\
\hline \multirow[t]{2}{*}{ - Training $\dagger$} & 0.8 & 0.5 & 0.7 & 0.5 & 0.5 & 0.7 & 0.7 & 0.6 \\
\hline & $(0.4-1.1)$ & $(0.2-0.7)$ & $(0.4-0.9)$ & $(0.2-0.7)$ & $(0.3-0.6)$ & $(0.5-0.9)$ & $(0.6-0.8)$ & $(0.5-0.7)$ \\
\hline \multirow[t]{2}{*}{ - Match play† } & 3.0 & 4.6 & 3.9 & 3.0 & 3.8 & 3.4 & 3.1 & 3.5 \\
\hline & $(1.8-4.0)$ & $(3.5-5.7)$ & $(2.6-4.7)$ & $(2.3-3.6)$ & $(2.9-4.7)$ & $(2.1-4.7)$ & $(2.0-4.1)$ & $(3.1-4.0)$ \\
\hline Absence/injury (days)* & $16(30)$ & $21(28)$ & $14(11)$ & $15(18)$ & $11(12)$ & $15(19)$ & $15(18)$ & $15(20)$ \\
\hline
\end{tabular}

* Values are mean (SD).

$\dagger$ Incidence expressed as injuries/1000 hours' exposure. Values within brackets are $95 \%$ confidence intervals.

Eighteen different diagnoses were registered in the hip/groin injury category, the most

frequent being adductor injury (64\%), followed by hip flexor/iliopsoas injury (8\%) (Table 3).

Table 3 Hip/groin injury diagnoses and number of injuries during the 2001/02-2007/08 seasons.

\begin{tabular}{|c|c|c|c|c|c|c|c|c|}
\hline & \multirow{2}{*}{$\begin{array}{l}\text { Injuries } \\
\text { n }(\%)\end{array}$} & \multirow[t]{2}{*}{ Incidence $\dagger$} & \multirow{2}{*}{$\begin{array}{l}\text { Re-injuries } \\
\text { n }(\%)\end{array}$} & \multicolumn{4}{|c|}{ Severity } & \multirow{2}{*}{$\begin{array}{l}\text { Absence } \\
\text { days: }\end{array}$} \\
\hline & & & & Minimal & Mild & Moderate & Severe & \\
\hline Adductor injury & $399(64)$ & 0.70 & $59(15)$ & 68 & 115 & 175 & 41 & $14(20)$ \\
\hline Hip flexor/iliopsoas injury & $52(8)$ & 0.09 & $2(4)$ & 11 & 19 & 20 & 2 & $11(10)$ \\
\hline $\begin{array}{l}\text { Rectus abdominis } \\
\text { tendinopathy }\end{array}$ & $14(2)$ & 0.02 & 2 & 1 & 5 & 6 & 2 & $17(15)$ \\
\hline Groin enthesiopathy & $8(1)$ & 0.01 & 3 & 3 & 0 & 1 & 4 & $27(25)$ \\
\hline Groin tendinopathy & $7(1)$ & 0.01 & 1 & 5 & 1 & 1 & 0 & $3(3)$ \\
\hline $\begin{array}{l}\text { Symphysitis/pelvic stress } \\
\text { fracture }\end{array}$ & $11(2)$ & 0.02 & 2 & 2 & 0 & 3 & 6 & $40(34)$ \\
\hline \multicolumn{9}{|l|}{ Hip joint injury } \\
\hline - Synovitis & $20(4)$ & 0.04 & $8(40)$ & 10 & 4 & 6 & 0 & $6(6)$ \\
\hline - Chondral lesion & $5(0.8)$ & 0.009 & 4 & 0 & 1 & 2 & 2 & $46(53)$ \\
\hline - Labral tear & $2(0.3)$ & 0.004 & 0 & 0 & 0 & 1 & 1 & $56(61)$ \\
\hline - FAI* & $2(0.3)$ & 0.004 & 2 & 0 & 0 & 1 & 1 & $64(60)$ \\
\hline - Sprain & $4(0.6)$ & 0.007 & 0 & 0 & 1 & 3 & 0 & $13(9)$ \\
\hline - Fracture (acetabulum) & $1(0.2)$ & 0.002 & 0 & 0 & 0 & 0 & 1 & 99 \\
\hline Hernia/sportsman's hernia & $22(4)$ & 0.04 & $4(18)$ & 0 & 3 & 9 & 10 & $30(17)$ \\
\hline Nerve entrapment & $3(0.5)$ & 0.005 & 0 & 0 & 1 & 1 & 1 & $29(27)$ \\
\hline Unspecified groin pain & $28(5)$ & 0.05 & $5(18)$ & 6 & 9 & 11 & 2 & $14(18)$ \\
\hline Other conditions $* *$ & $50(8)$ & 0.09 & 2 & 14 & 14 & 21 & 1 & $9(7)$ \\
\hline Total & 628 & 1.1 & 94 & 120 & 173 & 261 & 74 & $15(20)$ \\
\hline
\end{tabular}

* Femoroacetabular impingement

** Including gluteal/hip muscle pain/strain, haematoma/contusion hip region, trochanteric bursitis.

$\dagger$ Incidence expressed as injuries/1000 hours' exposure.

+ Mean (SD). 
There was no significant difference in groin injury incidence between age groups $(\mathrm{p}=0.4-0.9)$. It was between 1.0 and 1.2/1000 hours in the different age groups.

Preferred kicking leg was reported in 518 cases (players using right and left foot equally were excluded, as were bilaterally injured players) and injury side was analysed with respect to leg dominance. We found that 295 (57\%) groin injuries affected the dominant side and $223(43 \%)$ the non-dominant $(\mathrm{p}=0.89)$, thus leg dominance did not affect injury side.

Figure 1 shows the monthly variance of groin injury incidence. March was the month with the highest incidence of groin injuries throughout the seven seasons, followed by October and November.

Figure 1 near here.

\section{Investigations and correlation to diagnosis}

US and MRI were the two most commonly used investigations (Table 4). Other investigations used were plain X-ray $(n=16)$, bone scan $(n=3)$ and electromyography $(n=1)$. Adductor injuries and hip flexor/iliopsoas injuries were further analysed for differences in diagnostic frequency between different investigative modalities. This indicated that adductor injury was a more common diagnostic entity among injuries diagnosed with US or MRI than among injuries that were diagnosed by clinical examination only $(\mathrm{p}<0.0001)$. No such difference was seen for hip flexor/iliopsoas injuries $(\mathrm{p}=0.30)$. Remaining diagnoses were not analysed considering the small number of cases. 
Table 4 Frequency of selected diagnostic entities depending on method of examination during the 2005/062007/08 seasons.

\begin{tabular}{lllll}
\hline Diagnosis & Clinical only & US & MRI* & Total \\
\hline Adductor injury & $70(50)$ & $67(79)$ & $83(69)$ & $220(63)$ \\
Hip flexor/iliopsoas injury & $17(12)$ & $5(6)$ & $11(9)$ & $33(10)$ \\
Unspecified groin pain & $8(6)$ & $3(4)$ & $1(0.8)$ & $12(3)$ \\
Hernia/sportsman's hernia & $5(4)$ & $2(2)$ & $4(3)$ & $11(3)$ \\
Other conditions & $41(29)$ & $8(9)$ & $22(18)$ & $81(23)$ \\
Total & 141 & 85 & 121 & 347
\end{tabular}

Values are n (\%) per column. Percentage totals may be subject to rounding errors associated with individual components.

* 42 of the injuries investigated by both MRI and US were categorised in the MRI group. 


\section{DISCUSSION}

The main findings in the present study were that hip/groin injuries were a substantial problem in professional football and that more than half of the injuries resulted in the player being sidelined for more than one week. Another important finding was that re-injuries to the hip/groin constituted every sixth injury and caused significantly longer absences than index injuries.

\section{Injury incidence}

Consistent with other recent studies, ${ }^{3-6,12-14} 12-16 \%$ of all injuries acquired in professional football throughout a season were to the hip/groin. The incidence of injury in this study was consistent between seasons. To the best of our knowledge this has not been shown before and it indicates that groin injury is not an increasing problem in professional football.

\section{Injury severity and re-injury}

We found that $41 \%$ of groin injuries were classified as moderate and $12 \%$ as severe, which supports the earlier findings previously published for the first season of this cohort. ${ }^{13}$ Apparently, hip/groin injuries result in a rather long period of absence and preventive training would be beneficial. Scientifically validated prevention programmes are lacking, but exercises to increase joint movement ${ }^{22}$ and strengthen core and groin/gluteal muscles could be important. ${ }^{23}$ It is also plausible that increasing player and staff awareness (i.e. avoid playing with groin pain) could be an important factor.

Previous studies focusing on high-level footballers have reported a relatively high recurrence rate for groin injuries, ${ }^{5,14}$ ranging from $31-50 \%$. In the present study, we found that $15 \%$ of all groin injuries were re-injuries. This could partly be due to rather small numbers of 
analysed groin injuries in the previous studies, as well as increasing knowledge among the medical staff of elite clubs about treating groin injuries cautiously to minimise the risk of reinjury. Better organised medical support in Champions League clubs, as well as larger squads than in teams playing at lower levels, may give the opportunity to thoroughly rehabilitate and rest injured players. In this study, a time-limit of two months was used to define a recurrent injury, while other studies define these injuries as any other injury in the same location during the same season ${ }^{5}$ or earlier in the player's career, ${ }^{14}$ which could partly explain the discrepancies. Our finding that a re-injury in the groin area caused a significantly longer absence than the index injury further underlines the importance of a correct and quick diagnosis, as well as full rehabilitation before returning to play.

\section{Injury pattern and investigations}

Adductor-related injury was by far the most common diagnosis, representing almost threequarters of all cases together with iliopsoas-related injuries. This is in concordance with earlier studies. ${ }^{3,11}$ US and/or MRI was used in $68 \%$ of the cases in the adductor-related injury group, while the same investigations were used in less than $50 \%$ of cases in the iliopsoasrelated injury group in the 2005/06-2007/08 seasons. Diagnosis of almost every third adductor-related and every second iliopsoas-related injury was based solely on clinical examination. Adductor-related injuries were diagnosed more frequently with US (79\%) or MRI (69\%) than by clinical examination only (50\%), indicating that adductor-related injury is not overestimated when based on clinical examination only in the studied cohort. However, we did not have access to the MRI investigations or the statements of the radiologists responsible, therefore some investigations may have been normal and the diagnosis based on clinical symptoms anyway. Thus, overestimation of some diagnoses cannot be ruled out. 
The third most common entity was unspecified groin pain, representing $5 \%$ of the total number of hip/groin injuries. We interpret this as meaning that groin injuries are a troublesome area in clinical assessments and that there is a lack of documented guidelines for examining and diagnosing groin injury. Sportsman's hernia could constitute a part of this category, argued by some authors as a common but under-diagnosed source of unclear groin pain. ${ }^{8}$ In the present study, sportsman's hernia was diagnosed in $4 \%$ of the cases. Moreover, only 16 plain X-rays were conducted, a number that arguably could be too low considering the increasing knowledge of hip joint anomalies causing chronic groin pain. In recent years, femoroacetabular impingement and labral tears have gained interest as differential diagnoses for groin pain. We found a relatively small number of such cases but it is possible that the increased awareness and knowledge about this diagnostic entity along with improvements of MRI and arthroscopic techniques will result in an increased number of reported cases in the future.

Availability and user knowledge as well as local traditions influence the use of the different investigative modalities. The medical staffs in several of the investigated teams have access to US on a daily basis and are using it both to diagnose injuries and to monitor the rehabilitation process. Arguably, MRI is less user-dependent and has recently been shown to have an excellent level of specificity for groin injuries, ${ }^{24}$ but no study has yet shown that MRI is superior to US in diagnosing hip/groin injury.

\section{Seasonal variation}

March was found to be the month with the highest incidence of groin injuries, followed by October and November. This finding correlates with exposure to match play. A squad rotation policy, low-intensity training in these periods and thorough planning of the match schedule 
could be of value. May had the lowest incidence of all months during the competitive season, corresponding to the end of the season with lower match-play intensity.

\section{Study strengths and weaknesses}

The obvious strength of this study is that it was conducted with a prospective design, avoiding the risk of recall bias. Being conducted over several seasons in a homogenous population, to our knowledge our study comprises one of the largest samples of prospectively recorded hip and groin injuries in sports to date. The method used to record and classify data followed the consensus statement ${ }^{18}$ and has successfully been implemented in previous studies, making relevant comparisons between studies possible. Another strength of this study is that the hip/groin injuries were diagnosed by experienced club medical practitioners and that many injuries were examined radiologically.

Still, a limitation of this study is the lack of common definitions and diagnostic criteria for groin injuries. To minimise the risk of inter-rater differences, we supplied each medical team with a thorough manual with definitions and study examples. Nevertheless, diagnostic procedures rely on personal, club, local and national traditions and we had no specific criteria or timeframe for referral for radiological examination. This should be considered when interpreting the results. Furthermore, since we did not have access to the radiological statements, we do not know to what extent injuries had normal findings or multiple pathology on radiological examination. To be able to validate and standardise the categorisation of injuries in future studies, the MRI statements should be collected, or preferably the images could be reviewed by an independent radiologist. 
Finally, we also recognise the risk of underestimating some cases of groin pain, since only injuries resulting in absence from training or match play were registered. Due to the overuse nature of many groin injuries, it is often possible to play for some period with hip/groin pain without time loss and these cases were not registered under the current injury definition.

\section{Conclusion}

Groin injuries are common in professional football, the incidence studied over several seasons being consistent. More than $50 \%$ of groin injuries cause absences of more than one week and re-injuries cause significantly longer absences than index injuries, emphasising the importance of quick and correct diagnosis as well as thorough rehabilitation before return to play. Diagnosis still relies to a rather large extent on clinical examination and the value of radiological examinations and the use of independent radiologists to further sharpen diagnostics should be investigated further.

\section{What is already known on this topic?}

- Hip/groin injury is common in football.

- Diffuse symptoms make diagnosis of groin injury difficult and recognised diagnostic criteria is lacking.

\section{What this study adds?}

- Hip/groin injury incidence does not change over consecutive seasons.

- Re-injury in the hip/groin region causes a significantly longer absence than the index injury.

- Diagnosis of groin injury still relies to a large extent on clinical examination. 


\section{REFERENCES}

1 Renström P, Peterson L. Groin injuries in athletes. Br J Sports Med 1980;14:30-36.

2 Smodlaka V. Groin pain in soccer players. Phys Sports Med 1980;8:57-61.

3 Ekstrand J, Hilding J. The incidence and differential diagnosis of acute groin injuries in male soccer players. Scand J Med Sci Sports 1999;9:98-103.

4 Engström B, Forssblad M, Johansson C, Törnkvist H. Does a major knee injury definitely sideline an elite soccer player? Am J Sports Med 1990;18:101-5.

5 Hawkins RD, Fuller CW. A prospective epidemiological study of injuries in four English professional football clubs. Br J Sports Med 1999;33;196-203.

6 Hawkins RD, Hulse MA, Wilkinson C, Hodson A, Gibson M. The association football medical research programme: an audit of injuries in professional football. Br J Sports Med 2001;35:43-47.

7 Andersen TE, Tenga A, Engebretsen L, Bahr R. Video analysis of injuries and incidents in Norwegian professional football. Br J Sports Med 2004;38:626-631.

8 Meyers W, McKechnie A, Philippon M, Horner M, Zoga A, Devon O. Experience with “sports hernia" spanning two decades. Ann Surg 2008;248:656-665.

9 Ekberg O, Persson N, Abrahamsson P, Westlin N, Lilja B. Longstanding groin pain in athletes: a multidisciplinary approach. Sports Med 1988;6:56-61.

10 Hölmich P. Adductor-related groin pain in athletes. Sports Med Arthr Rev 1997;5:285291.

11 Hölmich P. Long-standing groin pain in sportspeople fall into three primary patterns, a “clinical entity" approach: a prospective study of 207 patients. Br J Sports Med 2007; 41:247-252. 
12 Hägglund M, Waldén M, Ekstrand J. Injury incidence and distribution in elite football a prospective study of the Danish and Swedish top divisions. Scand J Med Sci Sports 2005; 15:21-28.

13 Waldén M, Hägglund M, Ekstrand J. UEFA Champions League study: a prospective study of injuries in professional football during the 2001-2002 season. Br J Sports Med 2005;39:542-546.

14 Árnason Á, Gudmundsson Á, Dahl HA, Jóhansson E. Soccer injuries in Iceland. Scand J Med Sci Sports 1996;6:40-45.

15 Inklaar H. Soccer injuries. I: incidence and severity. Sports Med 1994;18:55-73.

16 Bradshaw C, Bundy M, Falvey E. The diagnosis of long standing groin pain: a prospective clinical cohort study. Br J Sports Med 2007;41:247-252.

17 Ekstrand J, Hägglund M, Waldén M. Injury incidence and injury patterns in professional football - the UEFA Injury Study. Br J Sports Med 2009, June 23 [Epub ahead of print].

18 Fuller CW, Ekstrand J, Junge A, Andersen TE, Bahr R, Dvorak J et al. Consensus statement on injury definitions and data collection procedures in studies of football (soccer) injuries. Br J Sports Med 2006;40:193-201.

19 Hägglund M, Waldén M, Bahr R, Ekstrand J. Methods for epidemiological study of injuries to professional football players: developing the UEFA model. Br J Sports Med 2005;39:340-346.

20 Orchard J. Orchard Sports Injury Classification System (OSICS). Sport Health 1993;11:39-41.

21 Hägglund M, Waldén M, Ekstrand J. Previous injury as a risk factor for injury in elite football: a prospective study over two consecutive seasons. Br J Sports Med 2006;40:767. 
22 Verall G, Slavotinek J, Barnes P, Esterman A, Oakeshott R, Spriggins A. Hip joint range of motion restriction precedes athletic chronic groin injury. J Sci Med Sport 2007;10:463466.

23 Hölmich P, Uhrskou P, Ulnits L, Kanstrup IL, Nielsen MB, Bjerg AM et al. Effectiveness of active physical training as treatment for longstanding adductor-related groin pain in athletes: randomised trial. Lancet 1999;353:439-443.

24 Zoga A, Kavanagh E, Omar I, Morrison W, Kouloris G, Lopez H et al. Athletic pubalgia and the "sports hernia": MR imaging findings. Radiology 2008;247:797-807.

\section{Funding}

The study was funded by grants from UEFA and the Swedish National Centre for Research in Sports.

\section{Competing interests}

None

\section{Ethical approval}

The study design underwent an ethical review and was approved by the UEFA Football Development Division and the UEFA Medical Committee.

The Corresponding Author has the right to grant on behalf of all authors and does grant on behalf of all authors, an exclusive licence (or non exclusive for government employees) on a worldwide basis to the BMJ Publishing Group Ltd and its licensees to permit this article (if accepted) to be published in BJSM and any other BMJ Group products and to exploit all subsidiary rights, as set out in our licence (http://bjsm.bmjjournals.com//ifora/licence.pdf). 


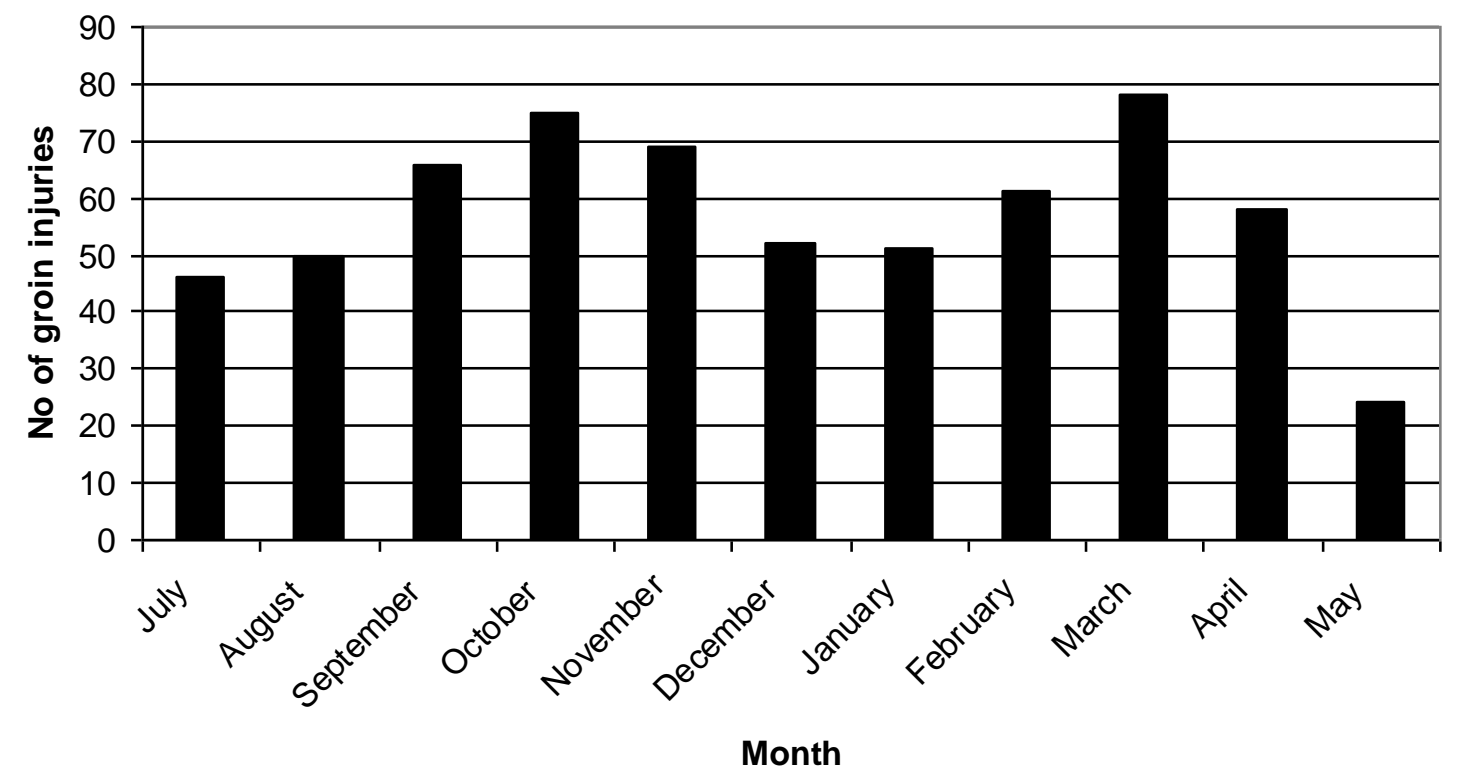

Figure 1 Groin injury incidence during training and match play, monthly distribution. 